\title{
External Skeletal Fixator Intramedullary Pin “Tie-in" for the Repair of Comminuted Tibial Fracture in a Brazilian Fox (Pseudalopex vetulus)
}

\author{
Guilherme Henrique Fernandes Barranco', Michelly Amanda Barssalho', Diego Alaska Almeida', Joana Zafalon \\ Ferreira' ${ }^{2}$, Sthephanie Fernandez ${ }^{3}$, Tatiana Morosini de Andrade Cruvinel' $\&$ Victor José Vieira Rossetto ${ }^{2}$
}

\begin{abstract}
Background: The Brazilian fox (Pseudalopex vetulus, Lund 1842) is a naturally endemic specie of the Brazilian savanna vegetation. Due to the rapid destruction of its habitat, the specie is considered "vulnerable" and subject to different kinds of trauma that usually results in fractures and dislocations. Among the methods of fractures fixation, highlights the external skeletal fixator intramedullary pin "tie-in" which consists of the intramedullary pin associated to the external fixator. The aim of the present report was to describe the case of a Brazilian fox with a comminuted tibial fracture, submitted to osteosynthesis using an external skeletal fixator intramedullary pin "tie-in".

Case: It was attended an exemplar of Pseudalopex vetulus, male, young adult, with $3.9 \mathrm{~kg}$ body weight and history of functional impotence of the left hindlimb. At the physical and orthopedic evaluations were observed loss of bone continuity and crepitus in tibial region, and the presence of a contaminated lacerating skin wound about $3 \mathrm{~cm}$ in diameter in the lateral side of the injured limb. Craniocaudal and mediolateral radiographic projections of the left hindlimb revealed the presence of a complete comminuted fracture at the proximal and distal shaft of the left tibia; and a complete transverse fracture at mid shaft of the left fibula. Due to this, the animal was submitted to fracture fixation using an external skeletal fixator intramedullary pin "tie-in". For the surgical procedure, broad trichotomy and antisepsis of the left hindlimb were performed, followed by a longitudinal incision on the medial side of the tibia. After bone fragments identification, was realized the retrograde positioning of a Steinmann pin of $3.0 \mathrm{~mm}$ in diameter toward the proximal epiphysis. Subsequently, the pin was externalized in the parapatelar region and then replaced toward the distal epiphysis. The intramedullary pin was not cut, but folded and attached to the transcortical pins of the unilateral external skeletal fixator using polymethylmethacrylate acrylic resin. For the unilateral external skeletal fixator were placed four Kirschner pin of $1.5 \mathrm{~mm}$ in diameter. Of these, two pins were placed at the proximal bone segment of the fracture, and two at the distal one. The central bone segment was not transfixed by pins. Radiographic postoperative examination revealed fracture reduction with good alignment of the bone fragments. The metallic implants were also well positioned. Bone healing was verified at 150 days postoperatively. At this moment, radiographic examination revealed calcified and ossified bone callus, and the maintenance of bone axis. The animal was reintroduced to nature.

Discussion: The external skeletal fixator intramedullary pin "tie-in" features biomechanical superiority to both intramedullary and external skeletal fixator pin, since it resists to rotational, bending and axial forces that act at the fracture. Additionally, it is a less expensive fracture fixation method, especially when replacing the lateral connecting rod by polymethylmethacrylate acrylic resin. It was concluded that the external skeletal fixator intramedullary pin "tie-in"can be considered viable in small wild mammals, such as the Brazilian fox (Pseudalopex vetulus), since it enabled the bone healing and the limb functionality. Further studies with a greater number of individuals, however, are necessary to evaluate the real applicability of the fracture fixation method.
\end{abstract}

Keywords: traumatology, osteosynthesis, wild animals.

${ }^{1}$ Serviço de Atendimento Clínico e Cirúrgico de Animais Selvagens, ${ }^{2}$ Serviço de Cirurgia e Anestesiologia de Animais de Companhia \& ${ }^{3}$ Serviço de Diagnóstico por Imagem, Centro Universitário de Rio Preto (UNIRP), São José do Rio Preto, SP, Brazil. CORRESPONDENCE: V.J.V. Rossetto [vjvrossetto@ hotmail.com - Tel.: +55 (14) 98145-5801]. Unidade Universitária II, BR 153, Km 69, s/n. CEP 13630-000 São José do Rio Preto, SP, Brazil. 
G.H.F. Barranco, M.A. Barssalho, D.A. Almeida, et al. 2016. External Skeletal Fixator Intramedullary Pin "Tie-in" for the Repair of Comminuted Tibial Fracture in a Brazilian Fox (Pseudalopex vetulus). Acta Scientiae Veterinariae. 44(Suppl 1): 174.

\section{INTRODUCTION}

The Brazilian fox (Pseudalopex vetulus, Lund $1842)$ is a naturally endemic specie of the Brazilian savanna vegetation. Because of the rapid destruction of its habitat, the specie is considered "vulnerable" and subject to different kinds of trauma that usually results in fractures and dislocations $[3,6]$. The anatomical conformation of these animals with long limbs predisposes the occurrence of long bones fractures, which often require surgical approach.

Among the fracture fixation methods, stands out the external skeletal fixator intramedullary pin "tiein", which consists of the association of intramedullary pin to an unilateral external skeletal fixator, due to its many advantages over such fixation methods when used alone $[1,5,7]$.

The aim of the present report is to describe the case of a Brazilian fox (P. vetulus) submitted to a comminuted tibial fracture fixation using an external skeletal fixator intramedullary pin "tie-in" with satisfactory bone healing postoperatively and full functional recovery of the injured limb.

\section{CASE}

It was attended an exemplar of Pseudalopex vetulus, male, young adult, with $3.9 \mathrm{~kg}$ body weight and history of functional impotence of the left hindlimb. At the physical and orthopedic evaluations were observed loss of bone continuity and crepitus in tibial region, and the presence of a contaminated lacerating skin wound about $3 \mathrm{~cm}$ in diameter in the lateral side of the injured limb.

Craniocaudal and mediolateral radiographic projections of the left hindlimb revealed the presence of a complete comminuted fracture at the proximal and distal shaft of the left tibia; and a complete transverse fracture at mid shaft of the left fibula (Figure 1 A \& B).

Due to this, the animal was subjected to the tibial fracture fixation using an external skeletal fixator intramedullary pin "tie-in". For this, premedication was performed with $0.015 \mathrm{mg} \mathrm{kg}^{-1}$ of acepromazine (Acepran $\left.0.2 \%{ }^{\circledR}\right)^{1}$ and $0.3 \mathrm{mg} \mathrm{kg}^{-1}$ of morphine $\left(\text { Dimorf }^{\circledR}\right)^{2}$, both administered intramuscularly. The anesthetic induction was performed with propofol dose effect $\left(\text { Propovan }^{\circledR}\right)^{2}$, administered intravenously, and the maintenance with isoflurane (Isoforine $\left.{ }^{\circledR}\right)^{2}$ diluted in oxygen. For the surgical procedure, broad trichotomy and antisepsis of the left hindlimb were performed, followed by a longitudinal incision on the medial side of the tibia. After bone fragments identification, was realized the retrograde positioning of a Steinmann pin of $3.0 \mathrm{~mm}$ in diameter toward the proximal epiphysis. Subsequently, the pin was externalized in the parapatelar region and then replaced toward the distal epiphysis. The intramedullary pin was not cut, but folded and attached to the transcortical pins of the unilateral external skeletal fixator using polymethylmethacrylate acrylic resin (Figure $2 \mathrm{~A} \& \mathrm{~B}$ ). For the unilateral external skeletal fixator were placed four Kirschner pin of 1.5 $\mathrm{mm}$ in diameter. Of these, two pins were placed at the proximal bone segment of the fracture, and two at the distal one. The central bone segment was not transfixed by pins (Figure $2 \mathrm{~A} \& \mathrm{~B}$ ).

After tibial fracture fixation, was performed the suture of the anatomical planes as routine. Postoperative management consisted of $30 \mathrm{mg} \mathrm{kg}^{-1}$ of cephalothin (Cefalotina sódica) $^{3}$, subcutaneously, BID, for 30 days; $2 \mathrm{mg} \mathrm{kg}^{-1}$ of tramadol hydrochloride $\left(\operatorname{Tramadon}^{\circledR}\right)^{2}$, subcutaneously, BID, for seven days; and $2 \mathrm{mg} \mathrm{kg}^{-1}$ of ranitidine hydrochloride (Cloridrato de ranitidina) ${ }^{4}$, subcutaneously, BID, for 30 days. The cleaning of the surgical wound and the pins was carried out every two days using $0.9 \%$ saline.

Radiographic postoperative examination revealed fracture reduction with good alignment of the

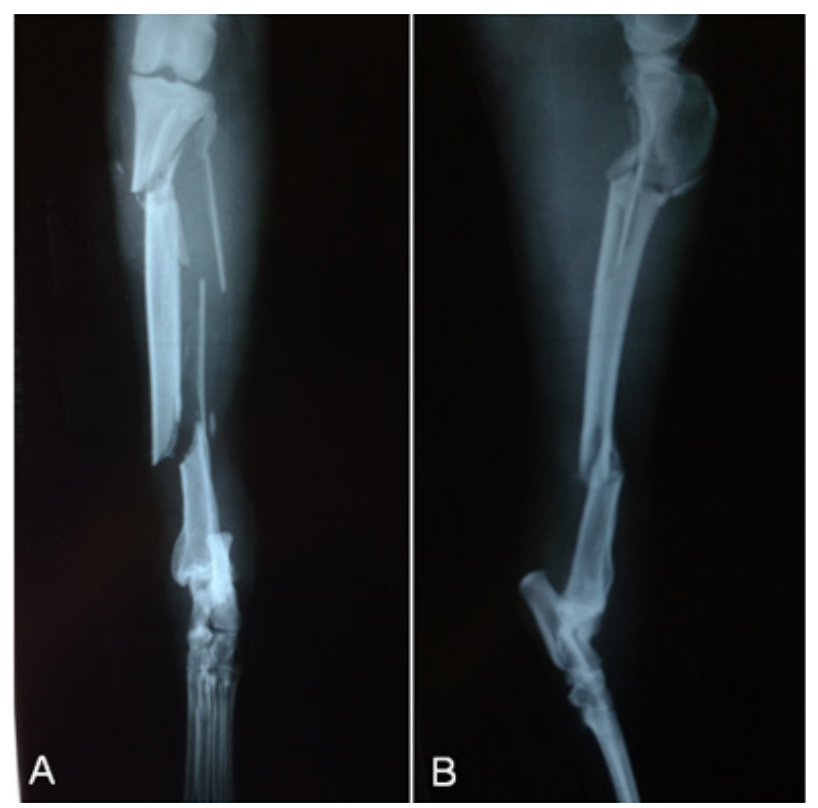

Figure 1. Perioperative craniocaudal (A) and mediolateral (B) radiographs of the left tibia and fibula of the Brazilian fox. Note the complete comminuted fracture at the proximal and distal shaft of the tibia with a slight deviation of the bone shaft; and a complete transverse fracture at the mid shaft of the fibula. 


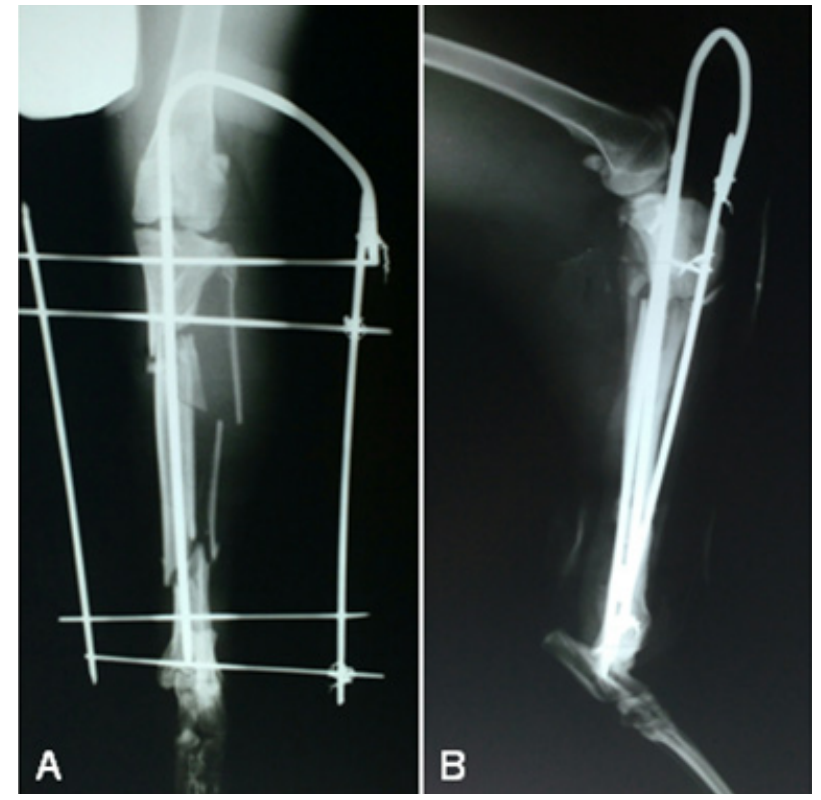

Figure 2. Immediate postoperative craniocaudal (A) and mediolateral (B) radiographs of the left tibia and fibula of the Brazilian Fox. Note the external skeletal fixator intramedullary pin "tie-in" and the proper alignment of the bone shaft.

bone fragments. The metallic implants were also well positioned (Figure 2A \& B).

The animal was evaluated every 30 days until bone healing on day 150 after surgery, when calcified and ossified bone callus were observed, with no visible fracture lines, along with the maintenance of the bone axis (Figure $3 \mathrm{~A} \& \mathrm{~B}$ ). At this moment, the animal was reintroduced to to its habitat.

\section{DISCUSSION}

The external skeletal fixator intramedullary pin "tie-in" features biomechanical superiority to both intramedullary and external skeletal fixator pin, since it resists to rotational, bending and axial forces that act at the fracture [2,7]. Additionally, it is a less expensive fracture fixation method, especially when replacing the lateral connecting rod by polymethylmethacrylate acrylic resin [5], as used in this case.

Although restored limb functionality, the bone healing time in the present case was considered superior to that described for small animals $[4,8]$. It is noted,
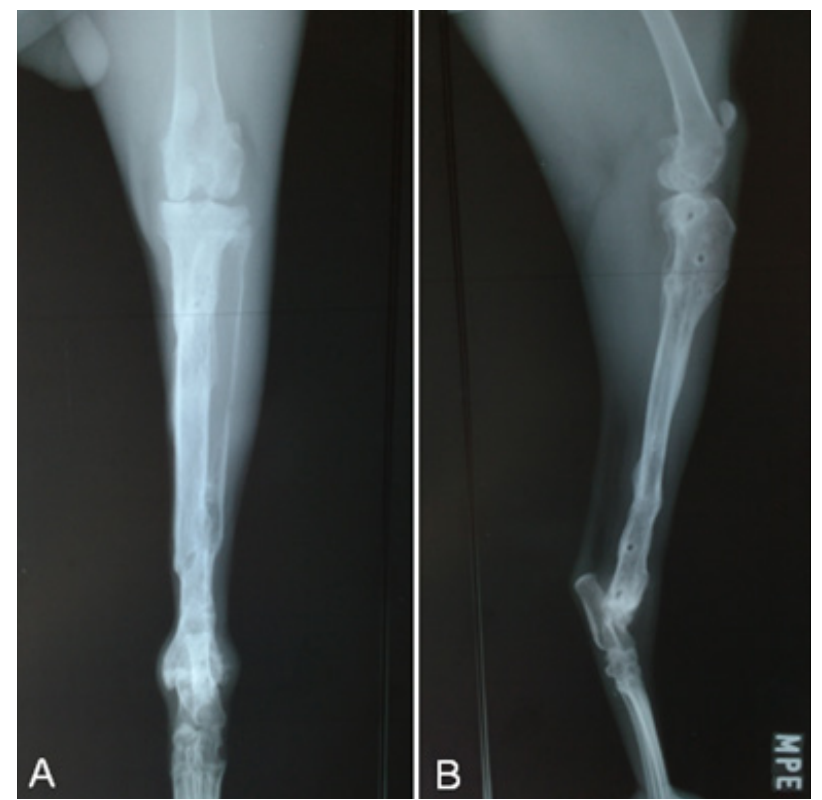

Figure 3. Postoperative craniocaudal (A) and mediolateral (B) radiographs within 30 days of the left tibia and fibula of the Brazilian Fox. Note the calcified bone callus and the absence of the fracture line with proper alignment of the bone shaft.

however, not be a normal pattern for comparison, since there are no studies with a sufficient number of individuals that describe the average bone healing time for the specie. Nevertheless, bone healing occurred without complications and the need of additional clinical or surgical intervention.

It was concluded that the external skeletal fixator intramedullary pin "tie-in" can be considered feasible in small wild mammals, such as the Brazilian fox (Pseudalopex vetulus), since it enabled the bone healing and the limb functionality. However, further studies with a greater number of individuals are necessary to evaluate the real applicability of the fracture fixation method.

\section{MANUFACTURERS}

${ }^{1}$ Vetnil Ind. e Com. de Produtos Veterinários Ltda. Louveira, SP, Brazil. ${ }^{2}$ Laboratório Cristália. São Paulo, SP, Brazil.

${ }^{3}$ Laboratório Teuto Brasileiro S.A. Anápolis, GO, Brazil.

${ }^{4}$ Medley Farmacêutica Ltda. Campinas, SP, Brazil.

Declaration of interest. The authors report no conflicts of interest. The authors alone are responsible for the content and writing of the paper.

\section{REFERENCES}

1 Aron D.N., Foutz T.L., Keller W.G. \& Brown J. 1991. Experimental and clinical experience with an IM pin external skeletal fixator tie-in configuration. Veterinary Comparative Orthopaedics and Traumatology. (4): 86-94.

2 Dallabrida A.L., Schossler J.E., De Aguiar E.S.V., Amendola G.F., Da Silva J.H.S. \& Soares J.M.D. 2005. Análise biomecânica ex-vivo de dois métodos de osteossíntese de fratura diafisária transversal em fêmur de cães. Ciência Rural. 35(1):116-120. 
G.H.F. Barranco, M.A. Barssalho, D.A. Almeida, et al. 2016. External Skeletal Fixator Intramedullary Pin "Tie-in" for the Repair of Comminuted Tibial Fracture in a Brazilian Fox (Pseudalopexvetulus). Acta Scientiae Veterinariae. 44(Suppl 1): 174.

3 Dalponte J.C. 2009. Lycalopex vetulus (Carnivora: Canidae). Mammalian Species. 847: 1-7.

4 Dennis R., Kirberger R.M., Barr F. \& Wrigley R.H. 2010. In. Handbook of small animal radiology and ultrasound. 2nd edn. St. Louis: Elsevier, 370p.

5 Johnson A.L. \& Hulse D.A. 2002. Fundamentals of orthopedic surgery and fracture management and management specific fractures. In: Fossum T.W., Hedlund C.S. \& Hulse D.A. (Eds). Small Animal Surgery. 2nd edn. St. Louis: Mosby, pp.821-1017.

6 Lemos F.G., Azevedo F.C., Beisiegel B.M. Jorge R.P.S., De Paula R.C., Rodrigues F. H.G. \& Rodrigues L.A. 2013. Avaliação do risco de extinção da raposa-do-campo, Lycalopex vetulus (Lund, 1842). Biodiversidade Brasileira. 3(1): 160-171.

7 Rahal S.C., Garib M.I., Matsubara M.F., Vulcano L.C. \& Louzada M.J.Q. 2004. Imobilização de fraturas femorais em gatos usando pino intramedular conectado ou não ao fixador esquelético externo. Revista Ciência Rural. 34(6): 1841-1847.

8 Roush J.K. 2005. Management of fractures in small animals. Veterinary Clinics of Small Animal Practice. 35(5): $1137-1154$. 